\title{
Fusarium Species Pathogenic to Barley and Their Associated Mycotoxins
}

\author{
B. Salas and B. J. Steffenson, Department of Plant Pathology, H. H. Casper and B. Tacke, Department of Veteri- \\ nary and Microbiological Sciences, L. K. Prom and T. G. Fetch, Jr., Department of Plant Pathology, and P. B. \\ Schwarz, Department of Cereal Science, North Dakota State University, Fargo 58105
}

\begin{abstract}
Salas, B., Steffenson, B. J., Casper, H. H., Tacke, B., Prom, L. K., Fetch, T. G., Jr., and Schwarz, P. B. 1999. Fusarium species pathogenic to barley and their associated mycotoxins. Plant Dis. 83:667-674.

Epidemics of Fusarium head blight (FHB) occurred on barley in Minnesota, North Dakota, and South Dakota from 1993 to 1998. The Red River Valley region was most severely impacted by the disease based on assessments of FHB severity in grain samples harvested from commercial fields. Fusarium graminearum was the primary pathogen causing these FHB epidemics. It comprised from 62 to 64\% of all Fusarium species isolated from infected kernels from 1994 to 1996. Fusarium poae (range of isolation 13 to $20 \%$ ), F. sporotrichioides (10 to $17 \%$ ), and $F$. avenaceum (6 to $10 \%$ ) also were isolated from barley kernels and were likely involved in causing some FHB infection, but to a very limited extent. All four Fusarium species were pathogenic on barley in inoculation tests conducted in both the greenhouse and the field. Mycotoxin screens were performed on barley spikes inoculated with the respective species in the greenhouse. Spikes infected with $F$. graminearum contained deoxynivalenol and 15-acetyldeoxynivalenol; those infected with $F$. sporotrichioides contained T-2 toxin, HT-2 toxin, and T-2 tetraol; and those infected with $F$. poae contained nivalenol. Some isolates of $F$. poae also produced 15acetoxyscirpenol and scirpentriol. Although $F$. graminearum and DON are recognized as the primary FHB pathogen and mycotoxin, respectively, in barley, the possible presence of other Fusarium species and mycotoxins should not be overlooked.
\end{abstract}

Additional keywords: deoxynivalenol, Fusarium head blight, Hordeum vulgare

The Upper Midwest region of Minnesota, North Dakota, and South Dakota is the largest production area for malting barley (Hordeum vulgare L.) in the United States. An annual average of over 450,000 ha of barley was harvested in the tri-state region from 1992 to 1996 (3). In 1993, a severe epidemic of Fusarium head blight (FHB) developed on the barley crop, causing an estimated yield loss of 1.6 million metric tons (20). FHB epidemics also occurred during the succeeding five seasons (1994 to 1998), again causing significant yield loss (33). In addition to reducing yield, FHB also severely impacted the quality of the crop (30). Since the 1993 FHB epidemic, one of the most important quality factors for malting barley has been the level of deoxynivalenol (DON), a mycotoxin produced by Fusarium graminearum Schwabe (teleomorph: Gibberella zeae (Schwein.) Petch). The widespread epidemics of FHB have rendered much of the region's barley crop unsuitable for malting and brewing because of DON contamination (33).

Corresponding author: B. J. Steffenson

E-mail: bsteffen@badlands.nodak.edu

Accepted for publication 19 March 1999.

Publication no. D-1999-0427-01R

(C) 1999 The American Phytopathological Society
In the United States, F. graminearum is considered the primary pathogen causing FHB in both barley $(10,19)$ and wheat $(32,39)$. It is likely that other Fusarium species cause FHB on barley in the Upper Midwest, since $F$. avenaceum (Fr.:Fr.) Sacc. (teleomorph: Gibberella avenacea R.J. Cook), F. sporotrichioides Sherb., F. poae (Peck) Wollenweb., and other species have been isolated from barley grain samples in North Dakota, Minnesota, and South Dakota (28). Despite the relatively frequent isolation of these Fusarium species from barley grain, little is known about their pathogenicity on barley and their distribution in the Upper Midwest. The objectives of this study were: (i) to determine the incidence of Fusarium species and also the severity of FHB in barley grain samples harvested from commercial fields, (ii) to assess the potential of these species as FHB pathogens of barley, and (iii) to assay the ability of these species to produce mycotoxins in barley. Preliminary reports of this research have been published $(27,28)$.

\section{MATERIALS AND METHODS}

Barley grain samples. Grain samples $(0.5$ to $1 \mathrm{~kg})$ were collected from randomly selected commercial barley fields in Minnesota, North Dakota, and South Dakota from 1993 to 1996 as part of the annual Midwest Barley Quality Survey conducted by the Department of Cereal Science at
North Dakota State University (4,5). Five malting cultivars comprise the bulk of the barley hectarage in the Upper Midwest. From 1993 to 1996, Robust comprised from 38.4 to $77.0 \%$, Stander 1.3 to $50.0 \%$, Excel 2.0 to $17.0 \%$, Morex 1.0 to $7.3 \%$, and Foster 1.2 to $3.7 \%$ of the hectarage in the region $(4,5)$. For these surveys, barley samples within each county of each cropreporting district in Minnesota (MN), North Dakota (ND), and South Dakota (SD) (Fig. 1) were included. After collection, samples were stored at $10^{\circ} \mathrm{C}$ and $\sim 30 \%$ relative humidity.

Isolation of Fusarium species. Incidence of Fusarium species infecting barley kernels in each year (1993 to 1996) was determined in the autumn of 1996. Fifty randomly selected kernels from each sample were plated on one of two culture media. Komada's medium (16), which is selective for Fusarium species, was used for the 1993 and 1994 samples, and acidified half-strength potato dextrose agar (AHSPDA) (10 g of dextrose, $100 \mathrm{~g}$ of potato, and $17.5 \mathrm{~g}$ of agar per liter of water at $\mathrm{pH}=5.5$ ), a general medium, was used for the 1995 and 1996 samples. In preliminary studies, we found that Komada's medium resulted in a slightly higher recovery rate for Fusarium isolates than AHSPDA (B. Salas and B. Steffenson, unpublished). However, initial species identifications were much easier to make on AHSPDA because the Fusarium isolates developed characteristic colonies. Thus, AHSPDA was the preferred medium for the general isolation of Fusarium from barley kernels. The viability of Fusarium in barley kernels can diminish over time $(6,31)$. This occurred in the older barley grain samples from 1993 and 1994. To enhance the recovery of Fusarium species in these samples, Komada's medium was used in place of AHSPDA.

All grain samples were surface sterilized before plating as follows: kernels were washed in running tap water for $5 \mathrm{~min}$, immersed in $75 \%$ ethanol for $30 \mathrm{~s}$ and then in $0.5 \% \mathrm{NaOCl}$ for $1 \mathrm{~min}$, rinsed twice in sterile distilled water, and finally dried under a laminar flow hood before plating. Previous studies had shown this surface sterilization technique to be effective for recovering a high percentage of Fusarium species from barley kernels without the interference of surface contaminating organisms (B. Salas and B. Steffenson, unpublished). Culture plates were incubated at 22 to $25^{\circ} \mathrm{C}$ with a $12-\mathrm{h}$ photoperiod 
provided by fluorescent (Philips F40CW/ RS/EW-11) and ultraviolet (General Electric F40BLB) lights emitting photons at 15 to $30 \mu \mathrm{mol} \cdot \mathrm{m}^{2} \cdot \mathrm{s}^{-1}$. After 5 to 7 days, all Fusarium colonies growing from kernels on AHSPDA were preliminarily assigned to species based on the arrangement of conidia and conidiophores under $\times 100$ magnification and also on the color of the colonies, according to the descriptions provided by Burgess et al. (7) and Nelson et al. (22). Fusarium colonies growing on Komada's medium were assigned to a particular species group based on various colony characteristics. Representative isolates of each Fusarium species or species group were transferred to fresh potato dextrose agar (PDA) (20 g of dextrose, 200 $\mathrm{g}$ of potato, and $20 \mathrm{~g}$ of agar per liter of water) slants, incubated for 5 to 7 days under the same conditions described above, and stored in a refrigerator at $4^{\circ} \mathrm{C}$ until needed. For the final species identification, cultures were removed from the refrigerator and incubated for 5 to 15 days to induce sporulation under the light and temperature regime previously described. Single conidial isolates were obtained by spreading a conidial suspension across a water agar culture plate and transferring a single germinated conidium to a new AHSPDA culture plate. Single spore cultures were grown on carnation leaf agar (CLA) $(32,38)$ for spore morphology assessment and on PDA for colony morphology and color assessment (22). Group 2 isolates of F. graminearum (11) were readily identi- fied by their ability to form perithecia on CLA (32,38). All other species were identified based on descriptions given in Burgess et al. (7) and Nelson et al. (22). Confirmation of species identification was made by C. M. Liddell, Department of Entomology, Plant Pathology, and Weed Science at New Mexico State University, Las Cruces. Representative isolates of the identified Fusarium species were deposited in the culture collection at the USDA-ARS National Center for Agricultural Utilization Research (NCAUR) in Peoria, Illinois (Table 1).

Greenhouse pathogenicity tests. The barley cultivar Stander (PI 564743) was used as primary host for pathogenicity tests of Fusarium isolates in the greenhouse. Barley seeds were sown in a peat moss:perlite (3:1 ratio) potting mix in 15 $\mathrm{cm}$ pots and grown in a greenhouse at 21 to $25^{\circ} \mathrm{C}$. Plants were inoculated when the kernels were between the midmilk to soft dough (Zadoks 75-85) stages of development (41). Single conidial isolates of $F$. graminearum, $F$. avenaceum, $F$. sporotrichioides, and $F$. poae from different locations within the region (Table 1) were tested for pathogenicity on barley. For the production of inoculum, isolates of $F$. avenaceum were grown on CLA, whereas isolates of $F$. graminearum, $F$. sporotrichioides, and $F$. poae were grown on AHSPDA. Previous research had shown these species to sporulate best on these respective media (B. Salas, unpublished). All isolates were incubated for 7 to 14 days as previously described. Macroconidia of $F$. graminearum and $F$. avenaceum, macroconidia plus microconidia of $F$. sporotrichioides, and microconidia of $F$. poae were harvested from culture plates by adding $10 \mathrm{ml}$ of sterile distilled water containing $0.02 \%$ polyoxyethylene-20sorbitan monolaurate (Tween 20) and then scraping the agar surface lightly with a sterilized rubber spatula. Conidial suspensions were filtered through four layers of cheesecloth and adjusted to 20,000 conidia per $\mathrm{ml}$ by adding additional volumes of sterile water. A concentration of 5,000 conidia per $\mathrm{ml}$ was used for $F$. graminearum because previous studies showed this concentration to be optimal for obtaining high levels of infection on barley spikes in the greenhouse (B. Salas, unpublished). An atomizer (Model 15, DeVilbiss Inc., Somerset, PA) pressured (60 kPa) by an air pump was used to deliver the conidial suspension onto plants at a rate of about $1.5 \mathrm{ml}$ per spike. Plants used as controls were sprayed with sterile distilled water. After inoculation, plants were incubated in mist chambers at $25^{\circ} \mathrm{C}$ for $48 \mathrm{~h}$, initially under $24 \mathrm{~h}$ of light (100 to 350 $\mu \mathrm{mol} \cdot \mathrm{m}^{2} \cdot \mathrm{s}^{-1}$ ) followed by $24 \mathrm{~h}$ of darkness. Then plants were transferred to a greenhouse at 21 to $25^{\circ} \mathrm{C}$, where FHB symptom development was assessed daily for 2 weeks. To complete Koch's postulates, reisolations were made from Fusariuminoculated and control (water sprayed) kernels. Resulting colonies were identified to species as described above. Remnant

\section{North Dakota}

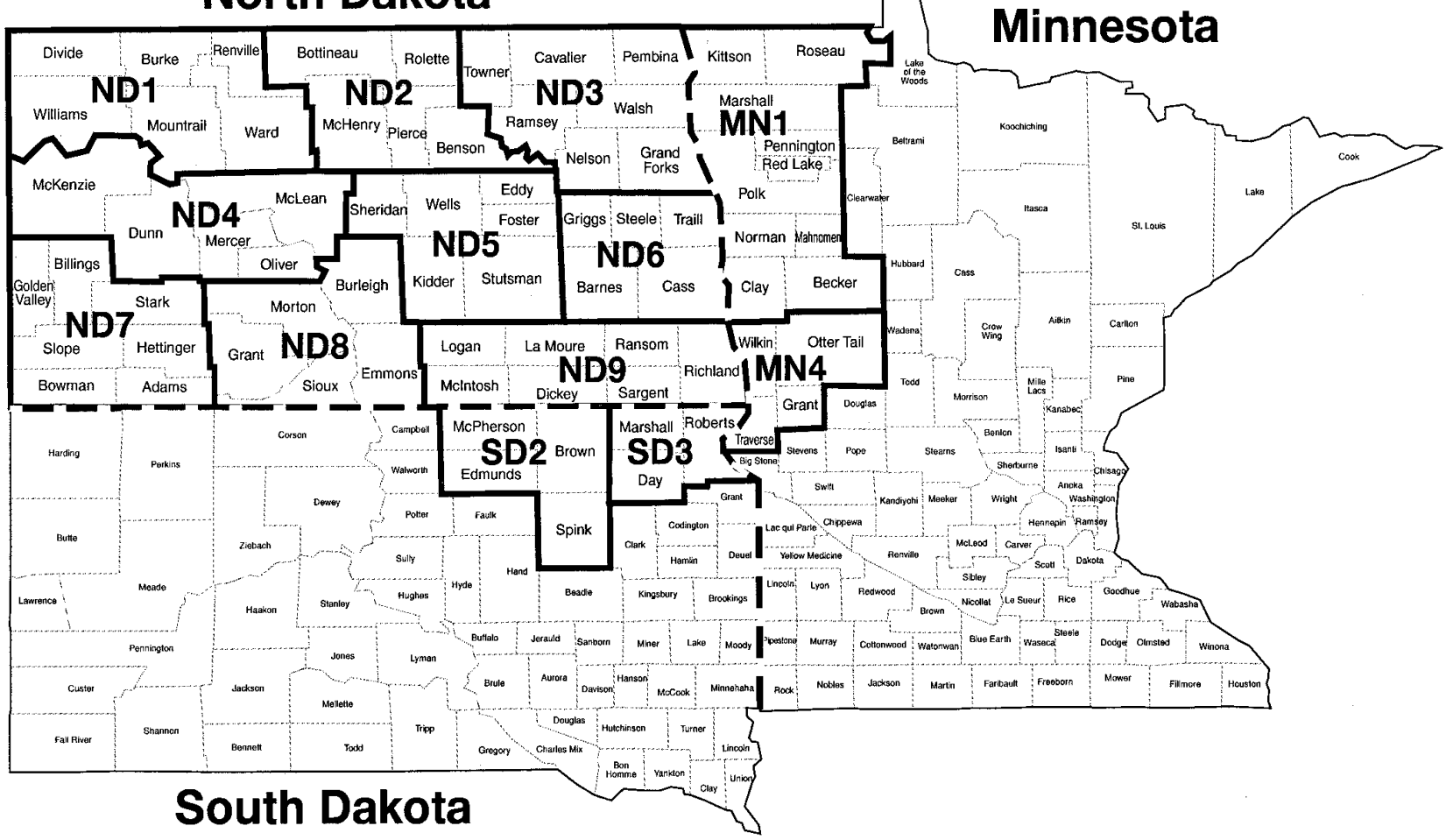

Fig. 1. Crop reporting districts of the major malting barley production areas in Minnesota, North Dakota, and South Dakota. 
intact spikes from these inoculation tests were assayed for mycotoxins.

Field pathogenicity tests. In 1996 and 1997, plots of Stander barley were established at the North Dakota State University Agricultural Research Station in Fargo to confirm the pathogenicity of $F$. graminearum, $F$. avenaceum, $F$. sporotrichioides, and $F$. poae under field conditions. A randomized complete block design with three replicates per species was used for the experiment. Plots were sown on 24 May and 15 May in 1996 and 1997, respectively. Each experimental unit consisted of four 3-m-long rows spaced $0.3 \mathrm{~m}$ apart. A 3-m-wide fallow area was left around each experimental unit to reduce interplot interference. Plants visually free of any natural FHB infection were inoculated at the soft dough stage (Zadoks 85) of development (41). A 300-ml conidial suspension $(20,000$ conidia per $\mathrm{ml}$ ) of each species was sprayed on about 100 spikes in the middle of each experimental unit on 25 July 1996 and 22 July 1997 between 2000 and 2100 hours. Inoculum for the respective species consisted of a composite of isolates $\mathrm{KB}$ 172, KB-176, and KB-582 for $F$. graminearum; KB-592, KB-664, and KB665 for $F$. avenaceum; KB-659, KB-660, and $\mathrm{KB}-662$ for $F$. sporotrichioides; and KB-600, KB-604, and KB-605 for F. poae. Control plots were sprayed with sterile distilled water. Immediately after inoculation, plants were covered with large plastic bags. The following morning (0800), bags were removed from the plants for the day and then replaced again during the evening
(2000) after misting the spikes with sterile distilled water. The morning thereafter, plants were left uncovered. Spikes were collected at random from the inoculated portion of each experimental unit (16 days postinoculation) for FHB ratings and reisolation and identification of the infecting pathogens.

Disease assessment. Five and 10 spikes per experimental unit or plot were collected and visually assessed for FHB infection on the kernels from the greenhouse and field experiments, respectively. Kernels with greater than $25 \%$ of their surface covered with lesions were considered blighted. For each spike, the number of blighted kernels and the total number of kernels were determined. The percent FHB severity in each spike was calculated by the formula: \% FHB severity $=$ (number of blighted kernels/total number of kernels) $\times$ 100.

For the Midwest Barley Quality Survey, 100 randomly selected kernels from each sample were assessed for FHB using the same criterion as previously described. FHB severity was also expressed as a percentage in these samples.

Mycotoxin determinations. Samples from the Midwest Barley Quality Survey were assayed for DON concentration only, whereas remnant intact spikes from the greenhouse pathogenicity tests were assayed for the presence of 17 mycotoxins (37), including DON. Mycotoxin assays were not made on samples from the field pathogenicity experiments because of natural and possibly cross-contamination of
Fusarium species among plots. Each grain $(5 \mathrm{~g})$ or spike (at least $2 \mathrm{~g}$ of tissue, including both kernels and the rachis) sample was ground and extracted with a fourfold volume of acetonitrile:water $(84+16)$ for 1 $\mathrm{h}$ on a horizontal shaker. A 6-ml aliquot of the supernatant was gravity filtered through a C18:Alumina $(1+1,1.5 \mathrm{~g})$ column. Two $\mathrm{ml}$ of eluent were evaporated under nitrogen at $55^{\circ} \mathrm{C}$ for $30 \mathrm{~min}$ and derivatized (TMSI+TMCS+BSTFA+Pyridine $1+1+1+1)$ to form trimethylsilyl (TMS) derivatives of 15 trichothecenes and two estrogenic mycotoxins. The TMS derivatives were assayed by gas chromatography/mass spectrometry with select ion monitoring (SIM) on a Finnigan Incos 50 mass spectrometer (Finnigan-Mat, San Jose, CA) using 3 to 4 ion fragments for identification and quantitation of each mycotoxin. The identity of the mycotoxins also was confirmed by full scan (50 to 650 $\mathrm{m} / \mathrm{z}$ ) mass spectrometry. The estimated detection limit was 0.5 ppm for all mycotoxins.

Correlation tests. Data for FHB severity, DON concentration, and isolation frequency of $F$. graminearum from the Midwest Barley Quality Survey were subjected to correlation tests to measure associations. Correlation tests were not made with $F$. poae, F. sporotrichioides, or $F$. avenaceum because their frequency of isolation was very low.

\section{RESULTS}

FHB severity, frequency of isolation of Fusarium species, and DON concentra-

Table 1. Information on representative isolates of Fusarium graminearum, F. avenaceum, F. sporotrichioides, and $F$. poae isolated from barley kernels in 1994 and 1995

\begin{tabular}{|c|c|c|c|c|c|c|c|}
\hline \multirow[b]{2}{*}{ Isolate } & \multirow{2}{*}{$\begin{array}{c}\text { NCAUR }^{a} \\
\text { number }\end{array}$} & \multirow[b]{2}{*}{ Species } & \multirow[b]{2}{*}{ Year collected } & \multirow{2}{*}{$\begin{array}{l}\text { Cultivar } \\
\text { of origin }\end{array}$} & \multicolumn{3}{|c|}{ Site of collection } \\
\hline & & & & & City & County & State \\
\hline KB-172 & 26938 & F. graminearum & 1994 & Robust & Woodworth & Stutsman & ND \\
\hline KB-582 & 26953 & F. graminearum & 1994 & $\ldots{ }^{c}$ & Ashley & McIntosh & ND \\
\hline KB-176 & 26939 & $F$. graminearum & 1994 & Robust & Rugby & Pierce & ND \\
\hline KB-672 & 26952 & F. graminearum & 1995 & Karl & Fargo & Cass & ND \\
\hline KB-587 & $\ldots{ }^{b}$ & $F$. graminearum & 1994 & $\ldots \mathrm{c}$ & Ludden & Dickey & ND \\
\hline KB-594 & 26949 & F. avenaceum & 1994 & $\ldots{ }^{c}$ & Leeds & Benson & ND \\
\hline KB-667 & $\ldots{ }^{b}$ & F. avenaceum & 1995 & Excel & Grandin & Cass & ND \\
\hline KB-665 & 26950 & F. avenaceum & 1995 & Foster & Grandin & Cass & ND \\
\hline KB-592 & 26951 & F. avenaceum & 1994 & $\ldots{ }^{c}$ & Kenmare & Ward & ND \\
\hline KB-664 & $\ldots{ }^{b}$ & F. avenaceum & 1995 & B2912 & Park River & Walsh & ND \\
\hline KB-662 & 26945 & F. sporotrichioides & 1995 & B2912 & Grandin & Cass & ND \\
\hline KB-610 & 26946 & F. sporotrichioides & 1994 & $\ldots{ }^{c}$ & Rolette & Rolette & ND \\
\hline KB-659 & 26947 & F. sporotrichioides & 1995 & Foster & Campbell & Wilkin & $\mathrm{MN}$ \\
\hline KB-565 & 26948 & F. sporotrichioides & 1995 & $\ldots{ }^{c}$ & Wolford & Pierce & ND \\
\hline KB-660 & $\ldots{ }^{b}$ & F. sporotrichioides & 1995 & Foster & New Effington & Roberts & SD \\
\hline KB-670 & $\ldots{ }^{b}$ & $F$. poae & 1995 & Chevron & Fargo & Cass & ND \\
\hline KB-652 & 26941 & F. poae & 1995 & Stander & Minot & Ward & ND \\
\hline KB-604 & $\ldots \mathrm{b}$ & F. poae & 1994 & $\ldots{ }^{c}$ & Sherwood & Renville & ND \\
\hline KB-605 & 26940 & F. poae & 1994 & $\ldots{ }^{c}$ & Bottineau & Bottineau & ND \\
\hline KB-534 & $\ldots \mathrm{b}$ & $F$. poae & 1994 & $\ldots{ }^{c}$ & Bottineau & Bottineau & ND \\
\hline KB-671 & $\ldots{ }^{b}$ & F. poae & 1995 & $\ldots{ }^{c}$ & Langdon & Cavalier & ND \\
\hline KB-654 & 26942 & F. poae & 1995 & B3213 & Minot & Ward & ND \\
\hline KB-600 & 26943 & F. poae & 1994 & $\ldots{ }^{c}$ & Kenmare & Ward & ND \\
\hline KB-609 & $\ldots{ }^{b}$ & F.poae & 1994 & $\ldots{ }^{c}$ & Beulah & Mercer & ND \\
\hline KB-656 & 26944 & F.poae & 1995 & Foster & New Effington & Roberts & $\mathrm{SD}$ \\
\hline
\end{tabular}

${ }^{a}$ Isolate number of the USDA-ARS National Center for Agricultural Utilization Research (NCAUR) culture collection.

${ }^{\mathrm{b}}$ Isolate not sent to NCAUR.

${ }^{\mathrm{c}}$ Information not available or not known. 
tion in samples from the Midwest Barley Quality Survey. The mean FHB severity across crop reporting districts ranged from 7.9 to $39.3 \%$ in 1993 (overall mean: $19.7 \%$ ), from 3.6 to $51.3 \%$ in 1994 (overall mean: $30.6 \%$ ), from 3.2 to $26.7 \%$ in 1995 (overall mean: 16.3\%), and from 6.2 to $39.1 \%$ in 1996 (overall mean: 25.1\%) (Table 2). In general, the highest FHB severities were observed in samples from the Red River Valley region (i.e., the border region between northwestern/west central Minnesota [crop reporting districts MN1 and MN4] and eastern North Dakota [ND3, ND6, and ND9]/northeastern South Dakota [SD2 and SD3]), and the lowest severities were observed in samples from northwestern North Dakota (ND1).

The recovery of Fusarium species from the 1993 samples was extremely low (data not shown) even though Komada's selective medium was used and a relatively high percentage $(19.7 \%)$ of the kernels appeared to be blighted. A similar but less extreme result occurred with the 1994 samples, where Komada's medium also was used. The overall mean percentage of isolation for Fusarium species $(5.1 \%$ for $F$. graminearum, $0.5 \%$ for $F$. poae, $1.1 \%$ for $F$. sporotrichioides, and $0.3 \%$ for $F$. avenaceum; data not shown) was low, despite the fact that samples from 1994 had the highest FHB severity (30.6\%) of any year in the survey (Table 2). AHSPDA was used for the isolation of Fusarium species in 1995 and 1996. The overall mean percentages of isolation for these 2 years, respectively, were 11.0 and $10.4 \%$ for $F$. graminearum, 1.6 and $0.6 \%$ for $F$. poae, 1.0 and $1.1 \%$ for $F$. sporotrichioides, and 0.3 and $0.5 \%$ for $F$. avenaceum. Other common fungi isolated from kernels on AHSPDA in 1995 and 1996 included Alternaria alternata (overall mean percentages of isolation: 77.6 and $80.5 \%$, respectively) and Cochliobolus sativus (3.4 and 2.9\%). For the 1994 samples, use of Komada's Fusarium selective medium precluded assessment of the isolation frequency of other fungi infecting barley.

$F$. graminearum was by far the most frequently isolated Fusarium species in the survey. It comprised 62,64 , and $64 \%$ of all Fusarium species isolated from infected kernels in 1994, 1995, and 1996, respectively (data not shown). F. graminearum was found in samples from every crop reporting district in each year where samples were analyzed (Fig. 1 and Table 2). The percentage of kernels infected by $F$. graminearum in individual samples ranged from 0 to $69.3 \%, 0$ to $64.0 \%$, and 0 to $72.0 \%$ for 1994, 1995, and 1996, respectively. The highest mean percentages of kernels infected by $F$. graminearum for a crop reporting district were $17.6 \%$ in 1994 (ND3), 21.5\% in 1995 (MN4), and 32.9\% in 1996 (ND3). In general, the highest percentage of kernels infected with $F$. graminearum was from samples collected in the Red River Valley crop reporting districts.

$F$. poae, $F$. sporotrichioides, and $F$. avenaceum were isolated from barley samples in each crop reporting district, but their mean frequency of isolation was low $(\leq 4.1 \%)$ (Table 2$)$. The percentages of kernels infected by the three species in individual samples for 1994, 1995, and 1996 ranged from 0 to $4.7 \%, 0$ to $10.0 \%$, and 0 to $4.0 \%$ for $F$. poae; 0 to $14.9 \%, 0$ to $8.0 \%$, and 0 to $14.0 \%$ for $F$. sporotrichioides; and 0 to $1.7 \%, 0$ to $4.0 \%$, and 0 to $4.0 \%$ for $F$. avenaceum, respectively. The highest mean percentages of kernels infected by the three species for a crop reporting district were $1.4 \%$ (ND3), $2.2 \%$ (MN1), and $1.3 \%$ (SD3) for $F$. poae; $4.1 \%$ (ND3), $2.0 \%$ (MN4), and $2.5 \%$ (ND5) for F. sporotrichioides; and 0.3\% (MN1, ND3, ND5, ND6, and SD3), 0.6\% (MN1 and ND2), and $1.2 \%$ (ND5) for $F$. avenaceum for the respective 3 years. As with $F$. graminearum, the highest percentage of kernels infected with these three species was from samples collected in the Red River Valley crop reporting districts.

Other Fusarium species occasionally isolated from barley kernels in the Midwest Barley Quality Survey included $F$. equiseti, F. acuminatum, F. scirpi, F. moniliforme, $F$. oxysporum, $F$. subglutinans, and $F$. culmorum.

DON was found in barley samples collected from all crop reporting districts in the Midwest Barley Quality Survey from 1993 to 1996, except for ND8, where data were not always available (Table 2). DON concentration in individual samples ranged from 0 to $16.0 \mathrm{ppm}, 0$ to $60.0 \mathrm{ppm}, 0$ to $24.4 \mathrm{ppm}$, and 0 to $25.8 \mathrm{ppm}$ for 1993 , 1994, 1995, and 1996, respectively. The highest mean DON concentration for a crop reporting district was $7.9 \mathrm{ppm}$ in 1993 (SD3), 21.8 ppm in 1994 (MN1), 10.8 ppm in 1995 (MN1), and $8.3 \mathrm{ppm}$ in 1996 (ND3). Samples collected in the Red River Valley crop reporting districts had the highest DON concentrations.

Greenhouse pathogenicity tests. All evaluated isolates of $F$. graminearum, $F$. avenaceum, $F$. sporotrichioides, and $F$. poae were pathogenic on kernels of Stander barley. FHB severity on spikes

Table 2. Fusarium head blight (FHB) severity, deoxynivalenol (DON) concentration, and isolation data for Fusarium graminearum, F. poae, F. sporotrichioides, and $F$. avenaceum in barley samples collected from 11 crop reporting districts in Minnesota, North Dakota, and South Dakota from 1993 to 1996

\begin{tabular}{|c|c|c|c|c|c|c|c|c|c|c|c|c|c|c|c|c|c|c|c|c|}
\hline \multirow{4}{*}{$\begin{array}{l}\text { State/ } \\
\text { crop } \\
\text { district }\end{array}$} & \multicolumn{20}{|c|}{ FHB severity (\%), DON concentration, and isolation data for Fusarium species } \\
\hline & \multicolumn{4}{|c|}{1993} & \multicolumn{12}{|c|}{1994} & \multicolumn{4}{|c|}{1995} \\
\hline & \multirow{2}{*}{\multicolumn{2}{|c|}{$\begin{array}{c}\text { Mean } \\
\text { FHB } \\
(\%)\end{array}$}} & \multicolumn{2}{|c|}{ DON $(\mathbf{p p m})^{\mathbf{b}}$} & \multirow[b]{2}{*}{$\mathbf{n}$} & \multirow{2}{*}{$\begin{array}{c}\text { Mean } \\
\text { FHB } \\
(\%)\end{array}$} & \multicolumn{2}{|c|}{ DON (ppm) } & \multicolumn{2}{|c|}{$\begin{array}{l}\text { F. gramin- } \\
\text { earum }^{\mathrm{c}}\end{array}$} & \multicolumn{2}{|c|}{ F.poae } & \multicolumn{2}{|c|}{$\begin{array}{c}\text { F.sporo- } \\
\text { trichioides }\end{array}$} & \multicolumn{2}{|c|}{$\begin{array}{c}F . \\
\text { avenaceum }\end{array}$} & \multirow{2}{*}{\multicolumn{2}{|c|}{$\begin{array}{rr} & \text { Mean } \\
& \text { FHB } \\
& \text { n } \quad(\%)\end{array}$}} & \multicolumn{2}{|c|}{ DON (ppm) } \\
\hline & & & Mean & Range & & & Mean & Range & Mean & Range & Mean & Range & Mean & Range & Mean & Range & & & Mean & Range \\
\hline \multicolumn{21}{|c|}{ North Dakota } \\
\hline ND1 & 8 & 7.9 & 0.1 & $0-0.3$ & 11 & 3.6 & 0.1 & $0-1.0$ & 0.8 & $0-3.4$ & 0.3 & $0-1.8$ & 0.4 & $0-3.1$ & 0.2 & $0-1.1$ & 9 & 4.0 & 0.3 & $0-2.6$ \\
\hline ND2 & 8 & 8.9 & 0.6 & $0-2$ & 9 & 4.6 & 1.2 & $0-3.3$ & 1.5 & $0-5.9$ & 0.4 & $0-2.1$ & 0.4 & $0-1.3$ & 0.0 & $0-0.3$ & 10 & 3.2 & 1.4 & $0-5.5$ \\
\hline ND3 & 11 & 12.2 & 2.7 & $0-5.1$ & 8 & 16.4 & 15.0 & $5.0-32.0$ & 17.6 & $0-69.3$ & 1.4 & $0-3.9$ & 4.1 & $0-14.9$ & 0.3 & $0-0.9$ & 14 & 12.9 & 7.6 & $1.1-24.4$ \\
\hline ND5 & 10 & 14.7 & 0.9 & $0-3.5$ & 10 & 34.2 & 2.8 & $0-10.0$ & 5.8 & $0-35.4$ & 1.1 & $0-4.6$ & 1.6 & $0-7.5$ & 0.3 & $0-1.5$ & 10 & 17.2 & 7.4 & $1.7-19.0$ \\
\hline ND6 & 10 & 12.8 & 6.8 & $2.6-14.0$ & 10 & 37.5 & 17.3 & $4.9-60.0$ & 6.7 & $0-17.8$ & 0.5 & $0-2.1$ & 1.3 & $0-2.9$ & 0.3 & $0-0.8$ & 9 & 26.7 & 7.7 & $4.7-14.8$ \\
\hline ND8 & $\ldots^{\mathrm{d}}$ & & & & 4 & 32.3 & & & 0.3 & $0-0.6$ & 0.2 & $0-0.7$ & 0.1 & $0-0.3$ & 0.1 & $0-0.3$ & 3 & 8.2 & 1.9 & $0.6-3.5$ \\
\hline ND9 & 15 & 23.4 & 4.2 & $0.6-8.5$ & 14 & 25.5 & 4.7 & $0-30.0$ & 7.3 & $0-45.4$ & 0.4 & $0-1.9$ & 1.5 & $0-7.3$ & 0.2 & $0-0.9$ & 10 & 11.8 & 3.3 & $0-11.4$ \\
\hline \multicolumn{21}{|c|}{ Minnesota } \\
\hline MN1 & 20 & 24.6 & 4.9 & $1.2-9.8$ & 20 & 48.4 & 21.8 & $3.5-52.0$ & 4.6 & $0-43.1$ & 0.5 & $0-3.5$ & 0.9 & $0-9.2$ & 0.3 & $0-1.0$ & 20 & 25.3 & 10.8 & $1.0-20.0$ \\
\hline MN4 & 10 & 28.4 & 6.2 & $3.4-8.4$ & 7 & 51.3 & 6.6 & 1.4-9.0 & 0.9 & $0-5.4$ & 0.1 & $0-0.2$ & 0.3 & $0-1.3$ & 0.1 & $0-0.3$ & 5 & 25.8 & 6.7 & $1.3-13.8$ \\
\hline \multicolumn{21}{|c|}{ South Dakota } \\
\hline SD2 & 7 & 29.6 & 5.8 & $0.9-12.3$ & 10 & 40.4 & 1.6 & & 0.1 & & 0.0 & $0-0.2$ & 0.1 & & 0.0 & $0-0.1$ & 5 & 15.7 & 0.6 & \\
\hline SD3 & 8 & 39.3 & 7.9 & $1.0-16.0$ & 8 & 31.8 & 3.9 & $0.7-13.0$ & 3.1 & $0-20.9$ & 0.8 & $0-4.7$ & 1.7 & $0-12.0$ & 0.3 & $0-1.7$ & 5 & 22.9 & 3.6 & $0.6-10.7$ \\
\hline
\end{tabular}

a Number of samples analyzed from each crop reporting district.

${ }^{\mathrm{b}}$ Mean and range of DON in barley samples within a crop reporting district.

${ }^{c}$ Mean percentage and range of kernels infected with the respective species of Fusarium in barley samples within a crop reporting district. Kernels were assayed for infection by plating on Komada's medium (1994 samples) or acidified half-strength potato dextrose agar (AHSPDA) medium (1995 and 1996 samples). Data for 1993 were not reported due to extremely low recovery of Fusarium species.

${ }^{\mathrm{d}}$ Data not available. 
ranged from 42 to $100 \%$ for isolate $\mathrm{KB}$ 172 of $F$. graminearum, 64 to $100 \%$ for isolates of $F$. avenaceum, 40 to $70 \%$ for isolates of $F$. sporotrichioides, and 16 to $76 \%$ for isolates of $F$. poae (Table 3 ). Generally, individual lesions caused by Fusarium covered more than one-quarter of the kernel. In many cases, the entire kernel was blighted within 7 to 10 days. Infections mostly started at the distal end of the lemma, but also were present on the middle and the basal end of this tissue. Fusarium infections extended beneath the lemma, as the pericarp of the kernel was often discolored, and the pathogen was recovered from this tissue. Lesions caused by $F$. graminearum, $F$. avenaceum, or $F$. sporotrichioides were mostly tan or brown to grayish brown in color and were difficult to distinguish from each other. Lesions caused by $F$. poae (isolate KB-652) usually had tan bleached centers with brown to grayish brown margins (19, see color plate 86); however, some kernels exhibited uniform grayish brown lesions, making it difficult to reliably differentiate the symptoms caused by this species from those caused by the other Fusarium species. Koch's postulates were completed for all isolates of each species in this experiment. The percent recovery of the respective species from inoculated kernels ranged from 18 to $48 \%$ for $F$. graminearum, 60 to $85 \%$ for $F$. avenaceum, 83 to $93 \%$ for $F$. sporotrichioides, and 70 to $88 \%$ for $F$. poae. No FHB symptoms were observed on control plants. Additionally, no Fusarium colonies were recovered from kernels after plating. A few colonies of $F$. graminearum were observed on plated kernels inoculated with the other respective species. This suggests that a low level of cross-contamination may have occurred in the experiment.

Field pathogenicity tests. All composite isolates of each Fusarium species caused FHB symptoms on barley kernels. The severity of FHB on Stander barley spikes in the respective inoculated plots ranged from 7 to $21 \%$ for $F$. graminearum, 4 to $11 \%$ for $F$. avenaceum, 2 to $11 \%$ for $F$. sporotrichioides, and 3 to $6 \%$ for $F$. poae over the 2-year study (Table 4). Natural or possibly cross-contamination occurred in the control plots to a limited extent as FHB severity ranged up to $3 \%$. From the reisolation tests of randomly selected kernels from respective plots inoculated with the different Fusarium species, 28 to $58 \%$ were infected with $F$. graminearum, 18 to $39 \%$ with $F$. avenaceum, 17 to $72 \%$ with $F$. sporotrichioides, and 2 to $8 \%$ with $F$. poae. Fungal isolations from the control plots revealed that 0 to $22 \%$ of randomly selected kernels were infected with $F$. graminearum, 0 to $2 \%$ with $F$. avenaceum, 0 to $10 \%$ with $F$. sporotrichioides, and 0 to $22 \%$ with $F$. poae.

Mycotoxin assays on inoculated spikes. The type and concentration of mycotoxins found in intact barley spikes from the greenhouse pathogenicity tests are reported in Table 3. All isolates of $F$. graminearum produced DON (range 14.4 to $56.0 \mathrm{ppm}$ ) and 15-acetyldeoxynivalenol (range 1.4 to $7.0 \mathrm{ppm}$ ), but one isolate (KB-582) also produced 3-acetyldeoxynivalenol at a concentration of $0.6 \mathrm{ppm}$, which is near the limit of detection (0.5 ppm) for the analytical equipment. DON also was detected in barley kernels inoculated with isolates of $F$. avenaceum (KB-
594, KB-667, and KB-665), F. sporotrichioides (KB-610), and $F$. poae (KB670, KB-652, KB-604, KB-609, KB-534, $\mathrm{KB}-671$, and KB-654); however, in most cases, the concentrations were near the threshold limit of detection. All five isolates of $F$. sporotrichioides produced $\mathrm{T}-2$ toxin (range 1.1 to $2.0 \mathrm{ppm}$ ), HT-2 toxin (range 6.7 to $10.8 \mathrm{ppm}$ ), and T-2 tetraol (range 1.9 to $9.7 \mathrm{ppm}$ ). One isolate of $F$. sporotrichioides (KB-662) also produced neosolaniol $(0.5 \mathrm{ppm})$, but at a concentration at the threshold limit of detection. Nivalenol was produced (range 1.2 to 5.3 ppm) by nine of the 10 isolates of $F$. poae tested. Most of these same isolates also produced 15-acetoxyscirpenol (range 0.6 to $1.9 \mathrm{ppm}$ ). Five of the $F$. poae isolates (KB670 , KB-652, KB-604, KB-600, and KB605 ) produced scirpentriol (range 0.8 to 1.5 $\mathrm{ppm})$. The mycotoxins diacetoxyscirpenol, $\mathrm{T}-2$ triol, iso-T-2 toxin, fusarenone-X, acetyl-T-2 toxin, zearalenol, and zearalenone were assayed, but they were not detected in any of the inoculated barley spikes. No mycotoxins were detected in the control samples.

Correlation tests. FHB severity was positively correlated with DON concentration (Table 5). The correlation between these two variables was highest in 1995 ( $r=$ $0.56)$ and lowest in $1996(r=0.31)$. The relationship between FHB severity and isolation frequency of $F$. graminearum was variable; a negative correlation was found in $1994(r=-0.19)$, and a positive correlation was found in $1995(r=0.45)$ and $1996(r=$ $0.32)$. DON was positively correlated with isolation frequency of $F$. graminearum. The correlation coefficients for these variables ranged from 0.28 in 1994 to 0.83 in 1996.

Table 2. (continued)

\begin{tabular}{|c|c|c|c|c|c|c|c|c|c|c|c|c|c|c|c|c|c|c|c|c|}
\hline \multirow{4}{*}{$\begin{array}{l}\text { State/ } \\
\text { crop } \\
\text { district }\end{array}$} & \multicolumn{20}{|c|}{ FHB severity (\%), DON concentration, and isolation data for Fusarium species } \\
\hline & \multicolumn{8}{|c|}{1995} & \multicolumn{12}{|c|}{1996} \\
\hline & \multicolumn{2}{|c|}{$\begin{array}{l}\text { F.gramin- } \\
\text { earum }\end{array}$} & \multicolumn{2}{|c|}{ F. poae } & \multicolumn{2}{|c|}{$\begin{array}{l}\text { F.sporo- } \\
\text { trichioides }\end{array}$} & \multicolumn{2}{|c|}{$\begin{array}{c}F . \\
\text { avenaceum }\end{array}$} & \multirow{2}{*}{\multicolumn{2}{|c|}{$\begin{array}{cc} & \text { Mean } \\
& \text { FHB } \\
\text { n } & (\%)\end{array}$}} & \multicolumn{2}{|c|}{ DON (ppm) } & \multicolumn{2}{|c|}{$\begin{array}{l}\text { F.gramin- } \\
\text { earum }\end{array}$} & \multicolumn{2}{|c|}{ F. poae } & \multicolumn{2}{|c|}{$\begin{array}{l}\text { F. sporo- } \\
\text { trichioides }\end{array}$} & \multicolumn{2}{|c|}{$\begin{array}{c}F . \\
\text { avenaceum }\end{array}$} \\
\hline & Mean & Range & Mean & Range & $\overline{\text { Mean }}$ & Range & Mean & Range & & & Mean & Range & Mean & Range & Mean & Range & Mean & Range & Mean & Range \\
\hline \multicolumn{21}{|c|}{ North Dakota } \\
\hline ND1 & 2.0 & $0-14.0$ & 1.2 & $0-6.0$ & 0.2 & $0-2.0$ & 0.5 & $0-4.0$ & 9 & 6.2 & 0.5 & $0-2.7$ & 2.8 & $0-14.0$ & 0.6 & $0-4.0$ & 0.8 & $0-4.0$ & 0.4 & $0-2.0$ \\
\hline ND2 & 5 & ( & 1.6 & $0-6.0$ & 0.8 & $0-6.0$ & 0.6 & $0-2$ & 9 & 12.5 & 4.8 & $0-25.8$ & 17.0 & & 0.8 & & 1.6 & $0-8.0$ & 0.8 & 0 \\
\hline ND3 & 17.9 & $0-64.0$ & 1.7 & $0-6.0$ & 0. & $0-2.0$ & 0.1 & $0-2.0$ & 14 & 30.7 & 8.3 & $0-21.6$ & 32.9 & $0-72$ & 0.4 & $0-4$ & 1.1 & $0-6$ & 0.7 & $0-4.0$ \\
\hline ND5 & 7.6 & $0-24.0$ & 1.4 & $0-6.0$ & 0.2 & $0-2.0$ & 0.0 & 0 & 12 & 33.3 & 3.2 & $0-7.9$ & 12.5 & $0-34.0$ & 1.2 & $0-4.0$ & 2.5 & $0-14.0$ & 1.2 & $0-4.0$ \\
\hline ND6 & 18.2 & $4-34.0$ & 1.2 & $0-8.0$ & 1.0 & $0-4.0$ & 0.0 & 0 & 10 & 33.9 & 5.0 & $0-10.9$ & 15.2 & $0-32.0$ & 0.6 & $0-2.0$ & 1.6 & $0-6.0$ & 0.8 & $0-2.0$ \\
\hline & 1.5 & & & & & & & 0 & & & & & & & & & & & & \\
\hline ND9 & 6.0 & $0-18.0$ & 2.0 & $0-6.0$ & 1.6 & $0-8.0$ & 0.4 & $0-2.0$ & 14 & 12.2 & 1.7 & $0-15.1$ & 2.4 & $0-8.0$ & 0.3 & $0-2.0$ & 0.9 & $0-4.0$ & 0.0 & 0 \\
\hline \multicolumn{21}{|c|}{ Minnesota } \\
\hline MN1 & 14.6 & $0-30.0$ & 2.2 & $0-10.0$ & 1.4 & $0-6.0$ & 0.6 & & 20 & 28.8 & 3.2 & $0-11.4$ & 6.9 & $0-32.0$ & 0.5 & $0-4.0$ & 0.6 & $0-4.0$ & 0.1 & $0-2.0$ \\
\hline MN4 & 21.5 & $0-62.0$ & 0.3 & $0-2.0$ & 2.0 & $0-6.0$ & 0.3 & $0-2.0$ & 8 & 30.9 & 0.9 & $0-5.9$ & 0.8 & $0-2.0$ & 0.8 & $0-2.0$ & 1.8 & $0-6.0$ & 0.3 & $0-2.0$ \\
\hline \multicolumn{21}{|c|}{ South Dakota } \\
\hline SD2 & 3.8 & $0-14.0$ & 1.8 & -6.0 & 1. & & 0. & & 7 & 25 & 0. & & 0. & & 0.7 & & 0.0 & & 0.3 & $0-2.0$ \\
\hline SD3 & 9.5 & $0-32.0$ & 1.3 & $0-6.0$ & 1.5 & $0-6.0$ & 0.5 & $0-2.0$ & 6 & 39.1 & 0.1 & $0-0.7$ & 1.0 & $0-4.0$ & 1.3 & $0-4.0$ & 0.3 & $0-2.0$ & 0.3 & $0-2.0$ \\
\hline
\end{tabular}




\section{DISCUSSION}

The FHB epidemics that occurred on barley over the past 6 years (1993 to 1998) in the Upper Midwest are apparently unprecedented for this important production region. Data obtained for FHB severity and DON concentration from the Midwest Barley Quality Survey (1993 to 1996) provide a means to assess the general distribution and magnitude of these epidemics. FHB was widely distributed, and the severity was variable throughout the tri-state region where samples were taken. The Red River Valley was most severely impacted by the disease. In the crop reporting districts that included the Red River Valley, mean levels of FHB and DON in harvested grain samples ranged from $11.8 \%$ (ND9 in 1995 ) to $51.3 \%$ (MN4 in 1994) and from $2.7 \mathrm{ppm}$ (ND3 in 1993) to $21.8 \mathrm{ppm}$ (MN1 in 1994), respectively (Fig. 1 and Table 2).
In contrast, mean levels of FHB and DON in northwestern North Dakota (ND1) ranged from $3.6 \%$ (1994) to $7.9 \%$ (1993) and from $0.1 \mathrm{ppm}$ (1993 and 1994) to 0.5 ppm (1996), respectively. Spore production and infection by $F$. graminearum are favored by moist weather conditions (36). The high severity of FHB in the Red River Valley was due largely to frequent rainfall that occurred during the crop heading period (33). FHB severity and DON concentrations were highest in 1994 and lowest in 1996. Work is in progress to analyze the same variables from the 1997 and 1998 seasons and also to estimate yield losses caused by FHB in barley (29).

The fungal isolation assays made on barley grain samples collected throughout the Upper Midwest clearly indicate that $F$. graminearum is the primary pathogen causing the recent FHB epidemics on bar- ley (Table 2). From 1994 to 1996, F. graminearum comprised 62 to $64 \%$ of all Fusarium species isolated from infected kernels. Similar results were found for 1993 and 1994 barley samples from Manitoba, Canada (2,9). F. graminearum also was the primary pathogen responsible for the FHB epidemics on the hard red spring and durum wheat crops in the Upper Midwest (20; R. W. Stack personal communication). This species is ubiquitous in the region, having been isolated from many different hosts and soil types $(13,26)$.

$F$. avenaceum, $F$. sporotrichioides, and $F$. poae also were isolated from barley kernels collected in the survey, but in much lower frequencies than $F$. graminearum (Table 2). These three species previously have been isolated from barley kernels $(2,8,9,13,18,34,35)$, the crowns and subcrown internodes of spring wheat (26), and

Table 3. Percent Fusarium head blight (FHB) severity and mycotoxins produced by four Fusarium species after inoculation on Stander barley in the greenhouse

\begin{tabular}{|c|c|c|c|c|c|c|c|c|c|c|c|c|}
\hline \multirow[b]{2}{*}{ Isolate } & \multirow[b]{2}{*}{ Fusarium species } & \multirow[b]{2}{*}{$\begin{array}{r}\% \text { FHB } \\
\text { severity }\end{array}$} & \multicolumn{10}{|c|}{ Mycotoxins (ppm) ${ }^{\mathrm{a}}$} \\
\hline & & & $\begin{array}{l}\text { Deoxynival- } \\
\text { enol(DON) }\end{array}$ & $\begin{array}{c}\text { 15-acetyl } \\
\text { DON }\end{array}$ & $\begin{array}{c}\text { 3-acetyl } \\
\text { DON }\end{array}$ & $\begin{array}{c}\text { Nival- } \\
\text { enol }\end{array}$ & $\begin{array}{l}\text { Scirp- } \\
\text { entriol }\end{array}$ & $\begin{array}{c}15 \text {-acetoxy- } \\
\text { scirpenol }\end{array}$ & $\begin{array}{c}\text { T-2 } \\
\text { toxin }\end{array}$ & $\begin{array}{l}\text { HT-2 } \\
\text { toxin }\end{array}$ & $\begin{array}{c}\text { T2- } \\
\text { tetraol }\end{array}$ & $\begin{array}{l}\text { Neoso- } \\
\text { laniol }\end{array}$ \\
\hline KB-172 & F. graminearum & $42-100^{\mathrm{b}}$ & 56.0 & 7.0 & $\ldots$ & $\ldots$ & $\ldots$ & $\ldots$ & $\ldots$ & $\ldots$ & $\ldots$ & $\ldots$ \\
\hline KB-672 & F. graminearum & $\ldots{ }^{c}$ & 33.1 & 5.9 & $\ldots$ & $\ldots$ & $\ldots$ & $\ldots$ & $\ldots$ & $\ldots$ & $\ldots$ & $\ldots$ \\
\hline KB-582 & F. graminearum & $\ldots$ & 21.8 & 4.1 & 0.6 & $\ldots$ & $\ldots$ & $\ldots$ & $\ldots$ & $\ldots$ & $\ldots$ & $\ldots$ \\
\hline KB-176 & F. graminearum & $\ldots$ & 14.9 & 1.4 & $\ldots$ & $\ldots$ & $\ldots$ & $\ldots$ & $\ldots$ & $\ldots$ & $\ldots$ & $\ldots$ \\
\hline KB-587 & F. graminearum & $\ldots$ & 14.4 & 3.4 & $\ldots$ & $\ldots$ & $\ldots$ & $\ldots$ & $\ldots$ & $\ldots$ & $\ldots$ & $\ldots$ \\
\hline KB-594 & F. avenaceum & 64 & 1.0 & $\ldots$ & $\ldots$ & $\ldots$ & $\ldots$ & $\ldots$ & $\ldots$ & $\ldots$ & $\ldots$ & $\ldots$ \\
\hline KB-667 & F. avenaceum & 94 & 0.6 & $\ldots$ & $\ldots$ & $\ldots$ & $\ldots$ & $\ldots$ & $\ldots$ & $\ldots$ & $\ldots$ & $\ldots$ \\
\hline KB-665 & F. avenaceum & 100 & 0.6 & $\ldots$ & $\ldots$ & $\ldots$ & $\ldots$ & $\ldots$ & $\ldots$ & $\ldots$ & $\ldots$ & $\ldots$ \\
\hline KB-592 & F. avenaceum & 68 & $\ldots$ & $\ldots$ & $\ldots$ & $\ldots$ & $\ldots$ & $\ldots$ & $\ldots$ & $\ldots$ & $\ldots$ & $\ldots$ \\
\hline KB-664 & F. avenaceum & 76 & $\ldots$ & $\ldots$ & $\ldots$ & $\ldots$ & $\ldots$ & $\ldots$ & $\ldots$ & $\ldots$ & $\ldots$ & $\ldots$ \\
\hline KB-610 & F. sporotrichioides & 40 & 1.3 & $\ldots$ & $\ldots$ & $\ldots$ & $\ldots$ & $\ldots$ & 1.8 & 9.0 & 5.7 & \\
\hline KB-662 & F. sporotrichioides & 54 & $\ldots$ & $\ldots$ & $\ldots$ & $\ldots$ & $\ldots$ & 0.5 & 2.0 & 10.8 & 9.7 & 0.5 \\
\hline KB-565 & F. sporotrichioides & 70 & $\ldots$ & $\ldots$ & $\ldots$ & $\ldots$ & $\ldots$ & 0.5 & 1.1 & 6.7 & 3.5 & $\ldots$ \\
\hline KB-659 & F. sporotrichioides & 68 & $\ldots$ & $\ldots$ & $\ldots$ & $\ldots$ & $\ldots$ & $\ldots$ & 1.4 & 7.0 & 4.6 & $\ldots$ \\
\hline KB-660 & F. sporotrichioides & 54 & $\ldots$ & $\ldots$ & $\ldots$ & $\ldots$ & $\ldots$ & $\ldots$ & 1.5 & 10.1 & 1.9 & $\ldots$ \\
\hline KB-670 & F. poae & $\ldots$ & $<0.5$ & $\ldots$ & $\ldots$ & 5.3 & 1.1 & 1.9 & $\ldots$ & $\ldots$ & $\ldots$ & $\ldots$ \\
\hline KB-652 & F. poae & 76 & $<0.5$ & $\ldots$ & $\ldots$ & 4.9 & 0.8 & 1.2 & $\ldots$ & $\ldots$ & $\ldots$ & $\ldots$ \\
\hline KB-604 & F. poae & 30 & 0.7 & $\ldots$ & $\ldots$ & 4.2 & 0.9 & 1.6 & $\ldots$ & $\ldots$ & $\ldots$ & $\ldots$ \\
\hline KB-609 & F. poae & 28 & 1.6 & $\ldots$ & $\ldots$ & 1.2 & $\ldots$ & 0.6 & $\ldots$ & $\ldots$ & $\ldots$ & $\ldots$ \\
\hline KB-534 & F. poae & 40 & 0.6 & $\ldots$ & $\ldots$ & 2.5 & $\ldots$ & 0.6 & $\ldots$ & $\ldots$ & $\ldots$ & $\ldots$ \\
\hline KB-671 & F. poae & $\ldots$ & 1.4 & $\ldots$ & $\ldots$ & 2.1 & $\ldots$ & 1.0 & $\ldots$ & $\ldots$ & $\ldots$ & $\ldots$ \\
\hline KB-654 & F. poae & 44 & 0.5 & $\ldots$ & $\ldots$ & 1.5 & $\ldots$ & 0.7 & $\ldots$ & $\ldots$ & $\ldots$ & $\ldots$ \\
\hline KB-600 & F. poae & 52 & $\ldots$ & $\ldots$ & $\ldots$ & 1.6 & 1.5 & $\ldots$ & $\ldots$ & $\ldots$ & 8.7 & $\ldots$ \\
\hline KB-605 & F. poae & 36 & $\ldots$ & $\ldots$ & $\ldots$ & 2.9 & 0.8 & 1.0 & $\ldots$ & $\ldots$ & $\ldots$ & $\ldots$ \\
\hline \multirow[t]{2}{*}{ KB-656 } & F. poae & 16 & $\ldots$ & $\ldots$ & $\ldots$ & $\ldots$ & $\ldots$ & $\ldots$ & $\ldots$ & 1.3 & $\ldots$ & $\ldots$ \\
\hline & Control & 0 & $\ldots$ & $\ldots$ & $\ldots$ & $\ldots$ & $\ldots$ & $\ldots$ & $\ldots$ & $\ldots$ & $\ldots$ & $\ldots$ \\
\hline
\end{tabular}

${ }^{a}$ A minimum of $2 \mathrm{~g}$ of tissue (barley kernels and the rachis) was used in the mycotoxin analysis for each isolate. The estimated limit of detection for mycotoxins was $0.5 \mathrm{ppm}$.

${ }^{\mathrm{b}}$ Data from a separate greenhouse inoculation on Stander barley.

${ }^{\mathrm{c}}$ Indicates data not taken for $\%$ FHB severity or mycotoxin not detected.

Table 4. Fusarium head blight (FHB) severity and isolation data for Fusarium species on Stander barley kernels inoculated with Fusarium graminearum, F. avenaceum, F. sporotrichioides, and F. poae in the field in 1996 and 1997

\begin{tabular}{|c|c|c|c|c|c|c|c|c|c|}
\hline & \multirow[b]{2}{*}{ Year } & \multicolumn{2}{|c|}{ F. graminearum } & \multicolumn{2}{|c|}{ F. avenaceum } & \multicolumn{2}{|c|}{ F. sporotrichioides } & \multicolumn{2}{|c|}{ F. poae } \\
\hline & & $\%$ FHB $^{a}$ & $\%$ isolation $^{b}$ & $\%$ FHB & $\%$ isolation & $\%$ FHB & $\%$ isolation & $\%$ FHB & $\%$ isolation \\
\hline Stander & 1996 & $7-13$ & $35-50$ & $9-11$ & $29-39$ & $5-7$ & $17-30$ & $3-6$ & $2-5$ \\
\hline Control & 1996 & $0-3$ & $0-4$ & $0-3$ & 0 & $0-3$ & $0-1$ & $0-3$ & $0-1$ \\
\hline Stander & 1997 & $15-21$ & $28-58$ & $4-9$ & $18-20$ & $2-11$ & $34-72$ & $3-4$ & $2-8$ \\
\hline Control & 1997 & $0-3$ & $6-22$ & $0-3$ & $0-2$ & $0-3$ & $4-10$ & $0-3$ & $4-22$ \\
\hline
\end{tabular}

${ }^{a}$ Range of FHB severity (\%) on Stander barley inoculated with the four respective species of Fusarium.

${ }^{\mathrm{b}}$ Range of isolation frequency (\%) of the four respective Fusarium species from inoculated kernels of Stander barley as assayed on acidified half-strength potato dextrose agar. 
blighted wheat spikes $(12,13,39)$ in North America. F. avenaceum previously was isolated in grassland soil (21) in North Dakota. F. sporotrichioides was reported from the roots of several grasses (14), and $F$. poae was reported from the roots of Bromus inermis (14) and soil (21) in North Dakota. Our results, together with some of the previously mentioned studies, indicate that $F$. avenaceum, $F$. sporotrichioides, and $F$. poae are widely distributed in the Upper Midwest region of the United States and may be fairly common components of the mycoflora of barley kernels. Similar results were also reported by Abramson et al. (2) in Manitoba. Outside of North America, Ichinoe et al. (15) in Japan, Kosiak et al. (17) in Norway, and Perkowski et al. (24) in Poland have isolated $F$. graminearum, $F$. avenaceum, $F$. sporotrichioides, and $F$. poae from barley kernels.

The results of greenhouse inoculation tests from this study show that isolates of $F$. avenaceum, $F$. sporotrichioides, and $F$. poae, in addition to $F$. graminearum, can cause FHB on barley kernels (Table 3). These results also were confirmed in field inoculation tests despite natural and/or cross-contamination problems among plots (Table 4). Perkowski et al. (24) artificially inoculated several barley cultivars in the field with $F$. graminearum, $F$. sporotrichioides, and F. culmorum and found all of them pathogenic. In another field inoculation test, Shands (31) found F. culmorum and $F$. avenaceum pathogenic on barley. It is possible that other Fusarium species may cause FHB on barley, because $F$. acuminatum, $F$. equiseti, $F$. scirpi, $F$. moniliforme, $F$. oxysporum, and F. subglutinans have been isolated from barley kernels in this and other studies $(13,15)$. Future investigations should be made to assess the pathogenicity of these other species on barley.

Ten mycotoxins (Table 3) were produced by the four Fusarium species in inoculated barley spikes from the greenhouse pathogenicity tests. The mycotoxins found for some of the Fusarium species in this study are in agreement with other studies. For example, Perkowski et al. (25) detected DON from barley artificially inoculated with $F$. graminearum. However, they also detected nivalenol, which was not found with the $F$. graminearum isolates tested in this study. Yoshizawa and Jin (40) also detected both DON and nivalenol, but in harvested grain samples infected with $F$. graminearum from the field. Perkowski et al. (24) recovered DON, 15-acetyldeoxynivalenol, 3-acetyldeoxynivalenol, zearalenone, and nivalenol in barley inoculated with $F$. graminearum, and T-2 toxin, HT-2 toxin, and neosolaniol in barley inoculated with $F$. sporotrichioides. The same mycotoxins were found for the respective species in this study, with the exception of zearalenone and nivalenol for $F$. graminearum. DON is generally considered the primary mycotoxin produced by $F$. graminearum, and this was confirmed in the present study. DON also was detected in barley spikes inoculated with at least one isolate of $F$. avenaceum, $F$. poae, and F. sporotrichioides. Although Abramson et al. (1) reported the production of DON by these three species in liquid culture, our results should be interpreted with caution because a few colonies of $F$. graminearum were isolated from plated kernels inoculated with $F$. avenaceum, $F$. poae, and $F$. sporotrichioides.

The presence of certain mycotoxins in barley kernels from this region may be suggestive of the presence of some Fusarium species. For example, the presence of DON and 15-acetyldeoxynivalenol may be suggestive of $F$. graminearum; the presence of T-2 toxin, HT-2 toxin, and T-2 tetraol may be suggestive of $F$. sporotrichioides; and the presence of nivalenol may be suggestive of $F$. poae (Table 3 ). Abramson et al. (1) isolated several Fusarium species, mainly from wheat collected in Manitoba, and reported the production of DON, 15-acetyldeoxynivalenol, HT-2 toxin, and nivalenol by $F$. graminearum, $F$. sporotrichioides, and $F$. poae in liquid culture. Thus, for complete confirmation, species identifications should be made in conjunction with mycotoxin screens in barley samples.

Although DON has been recognized as the primary mycotoxin in barley grain during the recent FHB epidemics in the Upper Midwest (30), the possible presence of other mycotoxins has not been thoroughly evaluated. Nivalenol is the only other mycotoxin that has been identified with some frequency from commercially produced barley (all near the threshold limit of detection) aside from DON and its derivatives 15-acetyldeoxynivalenol and 3acetyldeoxynivalenol (B. Salas and $\mathrm{H}$. $\mathrm{H}$. Casper, unpublished). The widespread distribution and virulence of $F$. sporotrichioides and $F$. poae on barley suggest the possibility of other mycotoxins being present on commercially produced barley grain. Thus, more complete mycotoxin screens (i.e., rather than just DON) may be warranted on barley samples containing a high incidence of $F$. sporotrichioides or $F$. poae.

In this study, the correlation coefficients between different pairs of variables were generally low. A positive, but weak correlation was found between FHB severity and DON concentration (Table 5). The low correlation coefficients (range of 0.38 to 0.56 ) found for these variables may be due to the misidentification of FHB lesions in grain samples (as $C$. sativus and A. alternata can cause similar kernel blight lesions) and the wide variation that can occur for DON concentration among kernel samples with the same level of disease (B. Steffenson and C. Henson, unpublished). Abramson et al. (2) studied the relationship between visible Fusarium mold on barley kernels (in levels of less than 5\%) and DON and found a correlation of 0.59 . The higher correlation found in that study was probably due to the fact that they used the actual sign or presence of the pathogen (i.e., the DON producer $F$. graminearum) as a criterion for their comparison. The relationship found between FHB severity and the frequency of isolation of $F$. graminearum was extremely variable in this study. A negative correlation was found for $1994(-0.19)$ samples, and a positive correlation was found for 1995 (0.45) and $1996(0.32)$ samples. The low positive correlation found in 1995 and 1996 may be due again to the misidentification of FHB lesions and possibly our inability to distinguish FHB lesions caused by species other than $F$. graminearum. The negative correlation found in 1994 may be related, in part, to the decreased viability of $F$. graminearum in kernels over time $(6,31)$. The 1994 samples were processed over 2 years after harvest, whereas the 1995 and 1996 samples were processed within 6 to 12 months after harvest. The decrease in $F$. graminearum viability, coupled with the constancy of kernel blight lesions (which remain relatively distinct over time), probably resulted in the negative correlation in 1994. The decreased viability of $F$. graminearum may also have contributed to the very low correlation ( $r=$

Table 5. Correlations for Fusarium head blight (FHB) severity, deoxynivalenol (DON) concentration, and isolation data for Fusarium graminearum in the Midwest Barley Quality Survey samples from 1993 to 1996

\begin{tabular}{|c|c|c|c|c|c|c|c|c|}
\hline \multirow[b]{2}{*}{ Comparison } & \multicolumn{2}{|c|}{$1993(n=107)^{a}$} & \multicolumn{2}{|c|}{$1994(n=101)$} & \multicolumn{2}{|c|}{$1995(n=100)$} & \multicolumn{2}{|c|}{$1996(n=109)$} \\
\hline & $r$ & $P$ value & $r$ & $P$ value & $r$ & $P$ value & $r$ & $P$ value \\
\hline FHB and DON & 0.47 & 0.0001 & 0.38 & 0.0001 & 0.56 & 0.0001 & 0.31 & 0.0012 \\
\hline FHB and $F$. graminearum & $\ldots^{\mathrm{b}}$ & $\ldots$ & -0.19 & 0.0626 & 0.45 & 0.0001 & 0.32 & 0.0006 \\
\hline DON and $F$. graminearum & $\ldots$ & $\ldots$ & 0.28 & 0.0041 & 0.54 & 0.0001 & 0.83 & 0.0001 \\
\hline
\end{tabular}

\footnotetext{
a Number of samples in correlation test.

${ }^{\mathrm{b}}$ Correlation tests not performed due to the extremely low frequency of isolation of $F$. graminearum in 1993.
} 
0.28 ) between DON concentration and the frequency of isolation of $F$. graminearum in 1994. Unlike the viability of $F$. graminearum, DON concentration remains relatively stable over time (6). The highest correlation found between DON concentration and isolation frequency of $F$. graminearum was 0.83 in 1996. Isolation assays for samples from 1996 were processed just a few months after harvest and likely before any significant decrease occurred in the viability of $F$. graminearum. Correlation coefficients of 0.79 and 0.71 were reported for these same variables in Canada for samples from 1993 and 1994, respectively (2).

Information on the impact of FHB on barley quality and yield has become an important consideration for buyers of this commodity since the 1993 epidemic. The Midwest Barley Quality Survey is ideal for assessing the impact of this disease because it provides a means to obtain a large number of random grain samples from commercial barley fields throughout the major production region. In addition to standard quality tests (5), DON assays are now routinely performed on barley samples by the Department of Cereal Science at North Dakota State University. This information, coupled with data on FHB severity, isolation frequency of Fusarium species, and yield loss (29), should provide a powerful means for assessing the impact and distribution of FHB on barley.

\section{ACKNOWLEDGMENTS}

We thank Renee Senn, Hilda Salas, and Denise Bucher for their technical assistance during the course of this project and J. Chelkowski and an anonymous reviewer for valuable comments on the manuscript. Financial support was provided in part by the American Malting Barley Association, North Dakota Barley Council, and North Dakota Agricultural Experiment Station.

\section{LITERATURE CITED}

1. Abramson, D., Clear, R. M., and Smith, D. M. 1993. Trichothecene production by Fusarium spp. isolated from Manitoba grain. Can. J. Plant Pathol. 15:147-152.

2. Abramson, D., Clear, R. M., Usleber, E., Gessler, R., Nowicki, T. W., and Märtlbauer, E. 1998. Fusarium species and 8-ketotrichothecene mycotoxins in Manitoba barley. Cereal Chem. 75:137-141.

3. Anonymous. 1999. Crop production 1998 summary. U.S. Dep. Agric., National Agricultural Statistics Service, Washington, DC

4. Anonymous. 1993-1995. Regional Barley Crop Quality Report. North Dakota Barley Council, Fargo.

5. Barr, J. M., Schwarz, P. B., Harrold, R. L., Bruns Olson, C., Kapphahn, M. E., and Gordon, D. T. 1996. Regional Barley Crop Quality Report. North Dakota Barley Council, Fargo.

6. Beattie, S., Schwarz, P. B., Horsley, R., Barr, J., and Casper, H. H. 1998. The effect of grain storage conditions on the viability of Fusarium and deoxynivalenol production in infested malting barley. J. Food Prot. 61:103106.

7. Burgess, L. W., Liddell, C. M., and Summerell, B. A. 1988. Laboratory manual for Fusarium research. Fusarium Research Laboratory, Department of Plant Pathology and Agricultural Entomology, University of Sydney, Sydney, Australia.

8. Cherewick, W. J., and Robinson, A. G. 1958. A rot of smutted inflorescences of cereals by Fusarium poae in association with the mite Siteroptes graminum. Phytopathology 48:232234.

9. Clear, R. M., Patrick, S. K., Platford, R. G., and Desjardins, M. 1996. Occurrence and distribution of Fusarium species in barley and oat seed from Manitoba in 1993 and 1994. Can. J. Plant Pathol. 18:409-414.

10. Dickson, J. G. 1942. Scab of wheat and barley and its control. U.S. Dep. Agric. Farmers' Bull. 1599. (Revised).

11. Francis, R. G., and Burgess, L. W. 1977. Characteristics of two populations of Fusarium roseum 'Graminearum' in eastern Australia. Trans. Br. Mycol. Soc. 68:421-427.

12. Gilbert, J., Tekauz, A., Mueller, E., and Kromer, U. 1994. Occurrence of Fusarium head blight in Manitoba in 1993. Can. Plant Dis. Surv. 74:77.

13. Gordon, W. L. 1959. The occurrence of Fusarium species in Canada. VI. Taxonomy and geographic distribution of Fusarium species on plants, insects, and fungi. Can. J. Bot. 37:257-290.

14. Gordon, W. L., and Sprague, R. 1941. Species of Fusarium associated with root rots of the gramineae in the northern Great Plains. Plant Dis. Rep. 25:168-180.

15. Ichinoe, M., Uchiyama, S., Amaro, R., and Kurata, H. 1985. Trichothecene-producing Fusarium in barley and wheat in Japan. Pages 21-32 in: Trichothecenes and other Mycotoxins. J. Lacey, ed. John Wiley \& Sons, New York.

16. Komada, H. 1975. Development of a selective medium for quantitative isolation of Fusarium oxysporum from natural soil. Rev. Plant Prot. Res. 8:114-125.

17. Kosiak, B., Torp, M., and Thrane, U. 1997. The occurrence of Fusarium spp. in Norwegian grain-A survey. Cereal Res. Commun. 25:595-596.

18. Martin, R. A., and Macleod, J. A., and Caldwell, C. 1991. Influences of production inputs on incidence of infection by Fusarium species on cereal seed. Plant Dis. 75:784-788.

19. Mathre, D. E., ed. 1997. Compendium of Barley Diseases. American Phytopathological Society, St. Paul, MN.

20. McMullen, M., Jones, R., and Gallenberg, D. 1997. Scab of wheat and barley: A re-emerging disease of devastating impact. Plant Dis. 81:1340-1348.

21. McMullen, M. P., and Stack, R. W. 1983. Fusarium species associated with grassland soils. Can. J. Bot. 61:2530-2538.

22. Nelson, P. E., Tousson, T. A., and Marasas, W. F. O. 1983. Fusarium species, an illustrated manual for identification. Pennsylvania State University, College Station.

23. O'Donnell, K., Cigelnik, E., and Casper, H. H. 1998. Molecular phylogenetic, morphological, and mycotoxin data support reidentification of the Quorn mycoprotein fungus as Fusarium venenatum. Fungic. Genet. Biol. 23:57-67.

24. Perkowski, J., Kiecana, I., and Chelkowski, J. 1995. Susceptibility of barley cultivars and lines to Fusarium infection and mycotoxin accumulation in kernels. J. Phytopathol. 143:547-551.

25. Perkowski, J., Kiecana, I., Schumacher, U., Muller, H. M., Chelkowski, J., and Golinski, P. 1997. Head infection and accumulation of Fusarium toxins in kernels of 12 barley genotypes inoculated with Fusarium graminearum isolates of two chemotypes. Eur. J. Plant Pathol. 103:85-90.

26. Salas, B. 1991. Effect of tillage and cropping systems on root rot of wheat. Ph.D. thesis North Dakota State University, Fargo.

27. Salas, B., Steffenson, B. J., and Casper, H. H. 1995. Incidence of Fusarium graminearum and vomitoxin levels in barley genotypes in North Dakota. (Abstr.) Phytopathology 85:1169.

28. Salas, B., Steffenson, B. J., Casper, H. H., and Prom, L. K. 1997. Fusarium species pathogenic to barley and their associated toxins. Cereal Res. Commun. 25:483-487.

29. Salas, B., Steffenson, B., Prom, L., and Fetch, T., Jr. 1996. A method to estimate yield loss in barley due to Fusarium head blight (Abstr.) Phytopathology 86:S58.

30. Schwarz, P. B., Casper, H. H., and Barr, J. M. 1995. Survey of the occurrence of deoxynivalenol (vomitoxin) in barley grown in $\mathrm{MN}$, ND, \& SD during 1993. Tech. Quart. MBAA 32:190-194.

31. Shands, R. G. 1937. Longevity of Gibberella saubinetii and other fungi in barley kernels and its relation to the emetic effect. Phytopathology 27:749-762.

32. Stack, R. W., and McMullen, M. 1985. Head blighting potential of Fusarium species associated with spring wheat head. Can. J. Plant Pathol. 7:79-82.

33. Steffenson, B. J. 1998. Fusarium head blight of barley: Epidemics, impact, and breeding for resistance. Tech. Quart. MBAA 35:177184.

34. Sturz, A. V., and Johnston, H. W. 1983. Early colonization of the ears of wheat and barley by Fusarium poae. Can. J. Plant Pathol. 5:107-110.

35. Sturz, A. V., and Johnston, H. W. 1985. Characterization of Fusarium colonization of spring barley and wheat produced on stubble or fallow soil. Can. J. Plant Pathol. 7:270276.

36. Sutton, J. C. 1982. Epidemiology of wheat head blight and maize ear rot caused by Fusarium graminearum. Can. J. Plant Pathol. 4:195-209.

37. Tacke, B. K., and Casper, H. H. 1996. Determination of deoxynivalenol in wheat, barley, and malt by column cleanup and gas chromatography with electron capture detection. J AOAC 79:472-475.

38. Tschanz, A. T., Horst, R. K., and Nelson, P. E. 1975. A substrate for uniform production of perithecia in Gibberella zeae. Mycologia 67:1101-1108.

39. Wilcoxson, R. D., Kommedahl, T., Ozmon, E. A., and Windels, C. E. 1988. Occurrence of Fusarium species in scabby wheat from Minnesota and their pathogenicity to wheat. Phytopathology 78:586-589.

40. Yoshizawa, T., and Jin, Y. 1995. Natural occurrence of acetylated derivatives of deoxynivalenol and nivalenol in wheat and barley in Japan. Food Addit. Contam. 12:689-694.

41. Zadoks, J. C., Chang, T. T., and Konzak, C. F. 1974. A decimal code for the growth stages of cereals. Weed Res. 14:415-421. 